\title{
Involvement of inflammatory cytokines in obesity and its complications
}

\author{
Mariana Cornelia Tilinca ${ }^{1}$, Eniko Csilla Barabas-Hajdu ${ }^{*}$, Gizella Tusa Ferencz ${ }^{2}$, \\ Eniko Nemes-Nagy ${ }^{1}$ \\ 1. University of Medicine and Pharmacy, Tirgu Mures \\ 2. Department of Internal Medicine and Hematology, University Hospital Linköping, Suedia
}

Received: $31^{\text {st }}$ August 2017; Accepted: $4^{\text {th }}$ May 2018; Published: $17^{\text {th }}$ June 2018

\section{Introduction}

Obesity represents a major social problem, especially in the developed countries, with growing incidence in adults and children, and it is associated with low-grade inflammation in the white adipose tissue (1). According to recent data, there are around 500 million adult obese individuals worldwide. The definition of obesity is based on the body mass index value (BMI), exceeding $30 \mathrm{~kg} / \mathrm{m}^{2}(2)$.

In the epidemiological study PREDATORR performed on 2,681 Romanian subjects, Popa and his collaborators found that obesity was present in $34.70 \%$ of the people included in the study group aged 20 to 79 years, while the metabolic syndrome was $38.50 \%$. The abdominal obesity represented $73.90 \%$ whereas the obesity rate adjusted for age and sex was $31.90 \%$. They concluded that there is a connection between obesity and kidney disease and several cardiometabolic factors (3). In the same study, glucose regulation disorders were detected in $28.1 \%$ of the subjects, leading to prediabetes, diagnosed or undiagnosed diabetes mellitus (4).

In contrast with our ancestors' protein-rich diet, nowadays the majority of people have a diet rich in carbohydrates and lipids. These individuals are very likely to gain weight, especially in the case of a sedentary lifestyle, which is also very common in countries with average- and high income (5). This mechanism may contribute to the development of insulin-resistance (6), another population-level problem regarding the increasing incidence of type 2 diabetes. The high-fat calorie consumption as a result of modern diet leads to increased concentration of polyunsaturated fatty acids (PUFA) with higher omega-6:omega-3 ratio, which can be precursors for several mediators, maintaining a chronic inflammatory state (7). This low-grade inflammation can trigger several chronic diseases such as obesity and osteoporosis (8). Recent research data revealed changes in the human brain due to obesity-related

*Corresponding author: Eniko Csilla Barabas-Hajdu, University of Medicine and Pharmacy Tirgu Mures, Romania.E-mail: eniko.barabas@gmail.com 
inflammation, caused by high sugar and fat intake. This kind of diet is preferred by individuals exposed to high levels of stress, probably based on neurochemical modifications induced in the central nervous system (9).

Cytokines are signaling molecules (mostly proteins, peptides) released by different cells, having an important role in immunoregulation, synthesis of blood cells and lymphocyte transformation. Each representative of this large family of molecules (including TNF - tumor necrosis factor) exhibits its effects by being attached to certain target cell receptors. The cytokine family includes several chemotactic molecules which participate to the signal transmission between the cells. Their secretion depends on cytokines that generate inflammation. Chemokines then act selectively on monocytes, lymphocytes and neutrophil leukocytes, the effect of different chemokines on the leukocytes depends on the chemokine receptors on their surface (10).

Several cytokines are secreted by adipocytes; many of these promote inflammation, the phenomenon being also enhanced in obesity due to the increased number of macrophages recruited in the adipose tissue (11).

\section{Main inflammatory and anti-inflammatory markers released in obesity}

\section{Classical cytokines secreted in the adipose tissue}

Chronic increase in the serum level of several pro-inflammatory cytokines can be observed in obese patients, such as tumor necrosis factor alpha (TNF- $\alpha$ ), interleukin-6 (IL-6), together with high-sensitive $\mathrm{C}$ reactive protein (hs-CRP), a marker of chronic, low grade inflammation (11). Based on some recent research data, hsCRP has been proved to be a more sensitive marker associated with obesity compared to IL-6 and TNF- $\alpha$ (1).
IL-6, according to a recent study, has been shown to inhibit subcutaneous adipogenesis. Secreted IL-6 presented a negative correlation with subcutaneous adipogenic capacity (12).

Obesity induces changes also in the cytokine secretion in macrophages, increasing the release of pro-inflammatory factors and reducing the anti-inflammatory ones. Infiltration of different $\mathrm{T}$ lymphocyte subtypes in the adipose tissue has also been reported (13). Research data are mainly obtained by studies performed on animals, and data obtained from patients are quite limited. Cytotoxic T cells enhance inflammation and insulin resistance in mice, while regulatory $\mathrm{T}$ cells have a protective role. The ratio of helper T1/T2 lymphocytes in visceral adipose tissue of obese patients positively correlates with plasma TNF- $\alpha$, CRP (C reactive protein) and IL- 6 , known as markers of systemic inflammation (6).

Leptin, responsible for regulation of food intake, is also an immune modulator; it exhibits pro-inflammatory and pro-aggregating effects. Based on evidence obtained from several studies, leptin stimulates the expression of pro-inflammatory cytokines in immune cells (polymorphonuclear neutrophils - PMN, T lymphocytes, monocytes, macrophages), thus contributing to the low-grade inflammation in the adipose tissue. The effect of leptin on PMN is by induction of TNF- $\alpha$ (14). Leptin also decreases the NO (nitric oxide) availability and thus contributes to the development of endothelial dysfunction, which plays a major role in the development of atherogenesis. A negative correlation was found by some researchers between leptin and adiponectin in human subjects (15).

In obesity, increased leptin and decreased adiponectin levels can be observed. Adiponectin has an anti-inflammatory effect and prevents atherosclerosis; its level is gender- and age-related: girls present higher adiponectin levels compared to boys, and its concentration decreases by ageing. Studies performed on obese children indi- 
cated an inverse correlation between adiponectin levels and BMI (body mass index). In adult patients, low levels of adiponectin were associated with the incidence of coronary disease and it was suggested to be considered an independent risk factor for the progression of type 2 diabetes (16). Adiponectin has three circulating isoforms based on their molecular weight (low, medium and high), the last one being considered to be a better metabolic marker than total adiponectin (17).

\section{Recently discovered cytokines released by the adipose tissue}

A new marker is, for example, resistin, also known as ADSF (adipose tissue-specific secretory factor), a recently described adipokine, belonging to the family of cysteine-rich proteins, containing 108 amino acids in its active form. Resistin links obesity to diabetes, it contributes to the development of insulin resistance, but several studies suggested its role as a modulator in inflammatory and autoimmune diseases, and also in the development of atherosclerosis (18).

Omentin is an adipokine discovered recently and it is secreted selectively in the visceral omental adipose tissue. Its concentration is decreased in overweight and obese patients having an impaired glucose regulation, in patients suffering from diabetes type 1 and 2 , and in patients with polycystic ovary syndrome. Obesity and leptin, insulin and glucose possibly regulate serum omentin levels (19). According to recent scientific data, low values of circulating omentin concentration can be in relationship with excessive deposits of visceral fat and with increased incidence of myocardial ischemia. Thus this substance is suggested as a potential biomarker of metabolic and cardiovascular disorders (20). Other studies revelead that high levels of plasma omentin are associated with improvement of ischemic heart injury and myocardial function after reperfusion in patients suffering from acute myocardial infarction. Studies on mice and on cultured cardiomyocytes showed that omentin suppresses myocyte apoptosis by enhancing the phosphorylation of certain enzymes (21). Significant increase could be observed in serum omentin concentration during weigh loss, this biomarker seems to be closely related to lipid metabolism (22).

Vaspin is a recently discovered adypokine, an enzyme inhibitor acting on the serine protease family, being a predictor of cardiovascular diseases, playing a connective role between overweight and carbohydrate metabolism disorders (23).

Apelin is an adipokine, but it is also secreted in many tissues including the heart, lung and brain, where it acts as a neurotransmitter (24). It influences the cardiovascular system, decreases blood pressure by causing vasodilation using a prostanoid-dependent mechanism, has a positive inotropic effect on the heart muscle (25). Recently it has been proven that it is an adipokine with higher plasma concentrations in obese patients and in type 2 diabetes. Studies suggest its role in the pathogenesis of diabetes (26). Apelin plays a role in the regulation of glucose homeostasis, has an impact also on lipid metabolism (27), energetic and nutritional status, inhibiting insulin secretion (28).

Another cytokine called chemerin showed higher concentration in elderly people compared to younger subjects and in overweight patients compared to those with normal BMI, all of these suffering from PCOS (polycystic ovary syndrome) $(29,30)$. Chemerin plays an important role in adipogenesis and energy metabolism, it is involved in the development of obesity, type 2 diabetes, metabolic syndrome and cardiovascular pathology (31). Chemerin acts as a stimulating factor for leukocyte migration to the areas affected by inflammation, such as at the level of the joints, enhancing the pro-inflammatory signalling in chondrocytes (32). 
IL-8 is an inflammatory cytokine (33), an adypokine showing significantly higher serum levels in patients with obesity compared to a group of patients with normal body weight (34). IL-8 is a mediator having a major role in progression and spreading of head and neck squamous cell carcinoma (35).

Cathepsin-S is a proteolytic enzyme containing cysteine residue in its active site, it has subclasses ( $\mathrm{S}, \mathrm{L}, \mathrm{K})$, the first subgroup is mostly related to the metabolism of adipocytes. Experimental data suggest that the inhibition of this enzyme could decrease the cardiovascular risk and improve metabolism in obese indiviuals (36).

In patients with weight excess, the adipose tissue releases factors which enhance angiogenesis. Data in the medical literature show that the vascular endothelial growth factor A (VEGF-A), which is generated by the intensified production of hormonal compounds and cytokines released by the adipose tissue, plays a central role in the formation of new vessels. Interactions mediated by this growth factor between endothelial cells and pancreatic beta-cells play an important role in the regeneration and differentiation of these endocrine cells (37). The VEGF-A molecule might become a target in future treatment of insulin resistance, obesity and related disorders (Elias I).

Granulocyte-colony stimulating factor (G-CSF) has a metabolic effect that resembles leptin and ciliary neurotrophic factor (CNTF), these substances having a major role in the energetics of the body. G-CSF is also an immune-modulator. In animal experiments on obese mice, G-CSF proved to help the weight loss and protected the heart from obesity-related impairment $(38,39,40)$. G-CSF induces mobilization and recruitment of neutrophils. G-CSF and also IL-6 are very likely to promote the expansion of myeloid-derived suppressor cells, which migh cause interferences with T cell activation and anti-tumor responses (41).
IL-1 $\beta$ (interleukin 1 beta) is a key mediator of the inflammatory response. It has been demonstrated that by enhancing inflammation at the level of the adipose tissue and by limiting fat expandability, IL-1 $\beta$ contributes to ectopic fat accumulation in hepatocytes and in the macrophages present in the fat-tissue, leading to compromised fat-liver crosstalk in nutritional obesity $(42)$. IL-1 $\beta$ is overproduced in obese patients by leucocytes. It binds to the IL-1 receptor and induces inflammatory gene expression. Inhibition of insulin signaling routes is caused by IL$1 \beta$ phosphorylation of insulin-receptor substrate 1 (IRS1) (43). Animal studies revealed that lack of IL-1 $\beta$, its receptor or NLRP3 inflammasome components are protective against the development of adipose tissue inflammation, furthermore, in type 2 diabetic patients the blockade of IL-1 mediated signaling improved glycemic control and reduced markers of systemic inflammation $(43,44)$.

RBP4 (Retinol Binding Protein 4) is a 21 $\mathrm{kDa}$ protein secreted by the liver cells and also by adipocytes and macrophages (45). It plays an important role in the regulation of glucose homeostasis. Animal experiments showed that expression of the RBP4 protein is inversely related to the number of type 4 glucose transporters, and in humans increased RBP4 levels are related to metabolic syndrome (46). RBP4 is also involved in the etiology of cardiovascular diseases. Experiments made on animals revealed that RBP4 contributes to the development of insulin resistance (47) and studies performed on humans confirmed this effect (45).

IL-18 has also been suggested to be produced by adipocytes, it has a pro-inflammatory effect, and its concentration increases in obese subjects. In animal experiments, high levels of IL-18 could be linked to aggravation of insulin resistance (48). A surprising discovery was that IL-18 in obesity and metabolic syndrome is a strong counteracting factor. Animal studies re- 
vealed that mice lacking IL-18 or IL-18R have developed obesity, insulin resistance, metabolic syndrome and by administration of recombinant IL-18 these processes are hindered, but the mechanism of this pathway or pathways is still unknown (43). Recent studies revealed that IL18 is activated by Caspase- 1 in inflammosome complexes and acts against obesity. Researchers observed in experiments on mice that animals lacking the NLRP1 inflammosome develop obesity spontaneously, just like those with IL-18 deficiency. Fat accumulation is increased especially in animals receiving a lipid- or protein-rich diet. It has been proved that mice having an activating mutation in NLRP1 leading to increased levels of IL-18 have reduced adiposity and show resistance to food-induced metabolic syndrome (49). Further studies are necessary to clarify the detailed mechanisms explaining the controversial metabolic effects of IL-18.

PAI-1 (plasminogen activator inhibitor type 1) is a glycoprotein produced by hepatocytes, endothelium cells and adipocytes. Its level is increased in insulin resistance and obesity. PAI-1 also acts as a cytokine modulator, regulating the expression of certain inflammatory factors such as IL-8 and leukotriene B4 (50). Plasmatic coagulation-related proteins, such as fibrinogen, PAI-1 and several inflammatory cytokines, such as TNF- $\alpha$, IL-1 $\beta$, IL-6 are increased in obese individuals due to persistent chronic inflammation (51). Nutritional factors, like free fatty acids (FFA), possess a regulatory effect on PAI-1 expression in macrophages. In raised concentrations of FFA in the bloodstream, an increase of PAI-1 gene expression in adipose tissue and adipose macrophages raised the concentration of circulating PAI-1 and higher PAI-1 protein production can be observed (52). Adipose cell size and adipose tissue mass are in positive correlation with circulating PAI-1 levels. The subcutaneous fatty tissue has a smaller contribution to the production of PAI-1 compared to the visceral adipose tissue. Insulin, glucocorticoids, angiotensin II, TNF $\alpha$ and TGF- $\beta$ can up-regulate PAI1 synthesis. Animal studies stated that in mice lacking PAI-1 gene, insulin resistance and obesity development was completely prevented by diet containing a high concentration of fat and carbohydrates (51).

Visfatin is released by many cell types, such as hepatocytes, muscle cells, bone marrow and it is also secreted by the adipose tissue, and its expression is related to obesity. A recent study showed a positive correlation between serum visfatin concentration and other inflammatory markers, such as CRP and IL-6 (53). Visfatin level is also correlated with fasting glucose, BMI and serum triglyceride concentration (54). The pathomechanism of visfatin effect is not completely clarified. Initially, an insulin-like effect was suggested due to its binding to the insulin receptor, but later this mechanism was not confirmed. A study on mouse pancreatic beta-cells revealed that visfatin changed the m-RNA (messanger ribonucleic acid) expression of some diabetes-related genes, including up-regulation of insulin secretion (55). Several studies reported elevated visfatin levels in obesity-related diseases, such as low-grade inflammation, type 2 diabetes mellitus, metabolic syndrome, cardiovascular diseases. In obese individuals, visfatin is secreted especially by the macrophages present in the visceral adipose tissue (56).

A recent study exposed that visfatin significantly increased at the transcript level the expression of the genes for several inflammatory markers such as IL- 6 and that of two CXC-cytokines (CXCL2, chemokine ligand 2 and CXCL8 chemokine ligand 8). The upregulation of the secretion of these two CXC-cytokines in a dose and time-dependent manner could also be observed. By investigating the interaction of visfatin-treated endothelial cells with leukocytes a significant increase in the adhesion to monocytes compared to endothelium cells not-treated with 
visfatin was shown. The suggested mechanism for these findings could be the upregulation of some adhesion marker expressions, such as E-Selectin, VCAM-1 and ICAM-1 (57).

ANGPTL2 (Angiopoietin-related peptide 2) has been recently described as an inflammatory cytokine released by the adipocytes which promote insulin resistance. Its serum concentration is positively correlated with the development of type 2 diabetes in human subjects (58). ANGPTL2 is involved in several age-related systemic diseases, it is also expressed in the eyes, and it is suggested to be involved in the regulation of choroid neovascularization which leads to macular degeneration (59).

SFRP5 (Secreted frizzled-related protein 5) is an anti-inflammatory cytokine, which is involved in glucose homeostasis, increasing insulin sensitivity. Recent studies revealed that it diminishes cardiac inflammation and exhibits a protective effect for the myocardium in ischemia-reperfusion injury (60).

\section{Pathological aspects}

Besides obesity and atherosclerosis, mild chronic inflammation occurs in many diseases affecting large groups of population worldwide, such as osteoarthritis, metabolic syndrome, diabetes, gallbladder disorders, non-alcoholic fatty liver disease (NAFLD) and some forms of cancer (2).

\section{Involvement of obesity-related cytokines in joint diseases}

Obesity is associated with rheumatoid arthritis (RA) due to the fact that in the fatty tissue a chronic inflammation occurs that may trigger a chronic systemic inflammation, thus, obese patients suffering from RA have more severe disease activity parameters, higher serum leptin levels and laboratory indices, and worse functional outcomes (61).
The metabolic pathways leading to osteoarthritis (OA) in overweight patients (BMI>30) are not completely known, although aberrant adipokine expression is thought to be involved, leading to joint tissue, cartilage, synovium and bone damage. Leptin and adiponectin receptors are expressed on the surface of chondrocytes, synoviocytes and subchondral osteoblasts, their levels are significantly elevated in patients with OA (62). A close relationship has been found between circulating adiponectin concentration and radiographic signs of rheumatoid arthritis in studied patient groups. Adiponectin very likely plays a role in the development of synovial inflammation in patients suffering from rheumatoid arthritis by stimulating the production of certain eicosanoids such as prostaglandin $\mathrm{E}_{2}$, interleukine 6 and 8 (63). Leptin receptors expressed on chondrocytes induce the synthesis of nitric oxide (NO), pro-inflammatory cytokines and matrix metalloproteinases that lead to cartilage destruction (64). Mechanoreceptors in the joint detect and convert the mechanical joint stress forces into intracellular signals that result in overexpression of prostaglandins, cytokines and chemokines (65). Reactive oxygen species are very likely to play an important role in this signaling (66). Studies on bovine cartilage showed that adiponectin (with and without synergic interaction with interleukine-1) induced collagene release from the cartilage, up-regulated proteolytic enzymes. Adiponectin's contribution to inflammation and degeneration of the cartilage explains the relationship between fat excess and ostheoarthritis (67).

A recent study revealed the differences in subcutaneous abdominal adipose tissue (SAAT) secretory activity between RA and OA patients. In RA, characterized by high-grade systemic inflammation, SAAT may contribute to cachexia, amyloidosis or development of cardiovascular diseases. In OA, characterized by low-grade systemic inflammation, adipokines released by the 
SAAT might play a role in the regulation of the intensity of systemic inflammation (68).

Insulin resistance might have a negative impact on the joint tissue, because of a local and a systemic effect. The local effect is due to insulin resistance of synovial membrane in diabetic patients, and the systemic effect derives from the state of a general low-grade inflammation related to obesity and insulin resistance (69).

The role of inflammation and oxidative stress in metabolic syndrome and diabetes mellitus

According to recent research data, inflammation of the adipose tissue has been described in association with metabolic syndrome (MS), this process being characterized by increased cytokine production and monocyte infiltration. Significant elevation of plasma CRP was described in obese patients compared to normal weight subjects, and also in the obese patients with MS compared to those without MS (70). Other inflammatory cytokines, such as TNF $\alpha$, IL-6 and IL-18 showed increased concentration only in obese subjects with MS. Oxidated LDL particles (Ox-LDL) have been measured to determine the level of oxidative stress, and were elevated in both obese groups, especially in those with MS. Based on the previously presented research data, we can assert that inflammation and increased oxidative stress could contribute to the development of MS (71). Another study described higher resistin levels in patients presenting MS compared to those without this pathology (72).

Oxidative stress can be evaluated by measuring the activity of antioxidant enzymes such as superoxide dismutase or glutathione peroxidase (73). Malondialdehyde (MDA) is another widely used marker of oxidative stress, it is increased in obesity and complications related to it (73). The majority of procedures are based on the MDA-thiobarbituric acid reaction. MDA reacts with the DNA (deoxyribonucleic acid), causes mutations, and forms deoxyguanosine adduct (dGA), which presents significantly lower concentration in individuals doing moderate or intense physical activity (74). Plasma lipid peroxidation level, determined by thibarbituric acid reactive substances (TBARS) was significantly higher in obese, diabetic, and obese-diabetic patients compared to control subjects (75). A seasonal variation can be observed in the metabolic control of diabetic patients, the suggested mechanism seems to be related to weight variation due to changes in physical activity and food intake during different seasons (76)--

\section{Obesity and non-alcoholic fatty liver disease}

Insulin resistance is an important underlying factor of non-alcoholic fatty liver disease, diabetes mellitus and cancer types in both normal weight and obese patients. Insulin resistant states can predict cardiometabolic disorders; insulin sensitivity evaluation could be beneficial especially in middle-aged subjects in order to identify those presenting a high risk of developing metabolic syndrome (77). Oxidative stress plays a major role in the development of the non-alcoholic fatty liver disease (73).

White adipose tissue (WAT) and brown adipose tissue (BAT) are the two distinct forms of adipose tissues. Initially scientists thought that BAT disappears after birth, but in fact, it is also present, in smaller amounts, in adults and its role is related to thermogenesis. Brown adipose tissue activity is in negative correlation with the BMI and its loss of activity may be related to WAT accumulation (78).

Adipose tissue inflammation, enhanced by IL-1 $\beta$, is now a well-recognized manifestation of obesity. This mediator also contributes to ectopic fat accumulation. IL-1 $\beta$ proved to have a major contribution to the communication dysfunction between adipocytes and liver cells, leading to insulin resistance of hepatocytes and steatosis (42). 


\section{Obesity-related cytokines in cardiac diseases}

Obesity is present in around $80 \%$ of the patients suffering from type 2 diabetes mellitus and is considered to be an independent risk factor for cardiovascular disease, its evaluation and treatment in these patients is extremely important. In a recent study performed on diabetic subjects, more male and female patients in the high-risk group for CHD had elevated BMI values than those included in the low-risk one (79).

An association has been observed between plasma resistin concentration and inflammatory chemokines such as monocyte chemoattractant protein 1 in non-diabetic adults with cardiovascular diseases (72).

Coronary heart disease (CHD) is a very common pathological condition. Multiple sources linked CHD to obesity. Several obesity-related cytokines are involved in cardiac diseases. IL-6 is a pro-atherogenic cytokine, and it may be a predictor of myocardial infarction risk (80).

TNF- $\alpha$ in animal models can have harmful effects on the cardiac muscle, depending on the cytokine amount and the exposure length. Neutralization of this cytokine led to attenuation of cardiac muscle damage after a cardiac event in mice (81).

Leptin has an important role in cardiovascular diseases. Leptin-deficiency can lead to increased mortality in viral myocarditis (82), higher cardiac remodeling grade induced by chronic ischaemia in different animal models (83).

Adiponectin has an important role in fatty acid catabolism and regulation of serum glucose level (84). Adiponectin concentration decreases in obesity and it is highly down-regulated in obese patients (85). Low serum levels of adiponectin can lead to coronary artery disease, hypertension and a greater risk of myocardial infarction (86). Adiponectin is a protective factor of cardiac myocytes, and adiponectin-deficient mice have shown a worse prognosis in different cardiovascular disease models. The protective effect of adiponectin in ischemia-reperfusion injury proved to be related to reduction of oxidative/nitrative stress (87).

According to recent studies, carotid intima-media thickness is positively associated with the RBP4 concentration (88). The level of this cytokine is related to an increased risk for developing cardiovascular diseases, and it may be a subclinical marker of atherosclerosis (89).

Investigating the role of cytokines in atherosclerosis, ANGPTL2 was found to enhance vascular inflammation by increasing macrophage infiltration and by activation of pro-inflammatory signalling in endothelial cells, causing endothelial dysfunction and progression of atherosclerosis (90).

In obese patients, a paradoxical phenomenon was described. According to numerous studies, the negative impact of obesity on most of the cardiovascular diseases has been shown. Despite the deleterious effect of obesity, recent studies have demonstrated the obesity paradox. Overweight patients and obese patients with cardiovascular diseases presented a better prognosis compared to patients with a normal body weight (91). The metabolic background of this paradox should be further investigated.

\section{Conclusions}

Cytokines released by the adipose tissue play a central role in obesity-related complications. Their main source is represented by adipocytes especially by the large white adipocytes located in visceral adiposity, and infiltrated macrophages, the majority of them exhibiting a pro-inflammatory effect. This pro-inflammatory status, maintained by increased levels of these bioactive molecules, represents a risk factor in the development and evolution of chronic diseases, be- 
ing involved in the occurrence of several major complications of the background disease.

Further studies are necessary to clarify all the details regarding the pathomechanisms of certain adipokines. Gathering new research data is crucial in this domain, because several cytokines (such as VEGF-A, IL-1 $\beta$ ) can be therapeutic targets in the treatment of obesity-related complications.

\section{Acknowledgements}

Financial support has been provided by a private research grant with the involvement of UMPh Tîrgu Mureș, contract no. 5068/26.04.2016.

\section{Conflict of interest}

The authors declare that there are no conflicts of interest.
Abbreviations
ADSF: adipose tissue-specific secretory factor ANGPTL2: angiopoietin-related peptide 2
BMI: body mass index
BAT: brown adipose tissue
CHD: Coronary heart disease
CL: chemokine ligand
CNTF: ciliary neurotrophic factor
CRP: $\mathrm{C}$ reactive protein
CXC: two cysteines separated by an amino acid
DNA: deoxyribonucleic acid
dGA: deoxyguanosine adduct
G-CSF: Granulocyte-colony stimulating factor
$11 \beta$-HSD: 11 beta-hydroxysteroid-dehydroge- nase (cortisone reductase)
HGF: hepatocyte growth factor
hs-CRP: high-sensitive $\mathrm{C}$ reactive protein
ICAM: intercellular adhesion molecule
IL: interleukin
MCP 1: monocyte chemoattractant protein 1
MDA: malondialdehyde

MS: metabolic syndrome

NAFLD: non-alcoholic fatty liver disease

NLPR3: NLR Family Pyrine Domain Containing 3

NO: nitric oxide

OA: osteoarthritis

PAI-1: plasminogen activator inhibitor type 1

PCOS: polycystic ovary syndrome

PMN: polymporphonuclear leukocytes (neutrophils)

PUFA: polyunsaturated fatty acids

RA: rheumatoid arthritis

RBP4: Retinol Binding Protein 4

SAAT: subcutaneous abdominal adipose tissue

SFRP5: secreted frizzled-related protein 5

TBARS: thiobarbituric acid reactive substances

TNF: tumor necrosis factor

VCAM: vascular cell adhesion molecule

VEGF-A: vascular endothelial growth factor A

WAT: white adipose tissue

\section{References}

1. Stepien M, Stepien A, Wlazel RN, Paradowski M, Banach M, Rysz J. Obesity indices and inflammatory markers in obese non-diabetic normo- and hypertensive patients: a comparative pilot study. Lipids Health Dis. 2014 Feb;13(1):29. DOI: 10.1186/1476-511X-13-29

2. Rodríguez-Hernández H, Simental-Mendía LE, Rodríguez-Ramírez G, Reyes-Romero MA. Obesity and inflammation: epidemiology, risk factors and markers of inflammation. Int J Endocrinol. 2013 Apr;17:1-11. DOI: $10.1155 / 2013 / 678159$

3. Popa S, Moţa M, Popa A, Moţa E, Serafinceanu C, Guja C et al. Prevalence of overweight/obesity, abdominal obesity and metabolic syndrome and atypical cardiometabolic phenotypes in the adult Romanian population: PREDATORR study. J Endocrinol Invest. 2016 Sep;39(9):1045-53. DOI: 10.1007/s40618-016-0470-4

4. Mota M, Popa SG, Mota E, Mitrea A, Catrinoiu D, Cheta DM et al. Prevalence of diabetes mellitus and prediabetes in the adult Romanian population: PREDATORR study. J Diabetes. 2016 May;8(3):336-44. DOI: 10.1111/1753-0407.12297

5. Grantham JP, Staub K, Rühli FJ, Henneberg M. Modern diet and metabolic variance-a recipe for disaster? Nutr J. 2014 Feb;13(1):15. DOI: 10.1186/1475-2891-13-15

6. Zeyda M, Huber J, Prager G, Stulnig TM. Inflammation correlates with markers of T-cells subsets includ- 
ing regulatory $\mathrm{T}$ cells in adipose tissue from obese patients. Obesity. 2011 Apr;19(4):743-8. DOI: 10.1038/ oby. 2010.123

7. Marventano S, Kolacz P, Castellano S, Galvano F, Buscemi S, Mistretta A, et al. A review of recent evidence in human studies of n-3 and n-6 PUFA intake on cardiovascular disease, cancer, and depressive disorders: does the ratio really matter?. Int J Food Sci Nutr. 2015 Aug;66(6):611-22. DOI: 10.3109/09637486.2015.1077790

8. Ilich JZ, Kelly OJ, Kim Y, Spicer MT. Low-grade chronic inflammation perpetuated by modern diet as a promoter of obesity and osteoporosis. Arh Hig Rada Toksikol. 2014 Jun;65(2):139-48. DOI: 10.2478/100041254-65-2014-2541

9. Morris MJ, Beilharz JE, Maniam J, Reichelt AC, Westbrook RF. Why is obesity such a problem in the 21 st century? The intersection of palatable food, cues and reward pathways, stress, and cognition. Neurosci Biobehav Rev. 2015 Nov;58:36-45. DOI: 10.1016/j. neubiorev.2014.12.002

10. Charo IF, Thaubman MB: Chemokines in the pathogenesis of vascular diseases, Circ Res. 2004;95:858-866. DOI: 10.1161/01.RES.0000146672.10582.17

11. Lasselin J, Magne E, Beau C, Ledaguenel P, Dexpert S, Aubert A, et al. Adipose Inflammation in Obesity: Relationship With Circulating Levels of Inflammatory Markers and Association With Surgery-Induced Weight Loss. J Clin Endocrinol Metab. 2014 Jan;99(1):E53-61. DOI: $10.1210 /$ jc. 2013-2673

12. Almuraikhy S, Kafienah W, Bashah M, Diboun I, Jaganjac M, Al-Khelaifi F, et al. Interleukin-6 induces impairment in human subcutaneous adipogenesis in obesity-associated insulin resistance. Diabetologia. 2016 Nov;59(11):2406-16. DOI: 10.1007/s00125-0164031-3

13. Orr SF, Kennedy AJ, Hasty AH: Isolation of Adipose Tissue Immune Cells, J Vis Exp. 2013;75:50707. DOI: $10.3791 / 50707$

14. Zarkesh-Esfahani H., Pockley AG, Z. Wu, Hellewell PG, Weetman AP, Ross RJM: Leptin indirectly activates human neutrophils via induction of TNF- $\alpha$. J Immunol. 2004;172(3):1809-1814. DOI: 10.4049/jimmunol.172.3.1809

15. Al-Hamodi Z, Molham AH, Al-Meeri A, Saif-Ali R. Association of adipokines, leptin/adiponectin ratio and C-reactive protein with obesity and type 2 diabetes mellitus. Diabetol Metab Syndr. 2014 Sep;6(1):99. DOI: 10.1186/1758-5996-6-99

16. Pires A, Martins P, Pereira AM, Marinho J, Silva PV, Marques M, et al. Pro-inflammatory triggers in childhood obesity: correlation between leptin, adiponectin and high-sensitivity C-reactive protein in a group of obese Portuguese children. Rev Port Cardiol. 2014 Nov;33(11):691-7. DOI: 10.1016/j.repc.2014.04.004
17. Nascimento H, Coimbra S, Rêgo C, Santos-Silva A, Belo L. Adiponectin, Inflammation and Cardiometabolic Risk Factors in Paediatric Obese Patients: Impact of Interventional Studies, Ed. Gordeladze JO, in Adiposity-Omics and Molecular Understanding, Ed. InTech, Croatia, 2017, 83-111.

18. Jamaluddin MS, Weakley SM, Yao Q, Chen C. Resistin: functional roles and therapeutic considerations for cardiovascular disease. $\mathrm{Br} \mathrm{J}$ Pharmacol. 2012 Feb;165(3):622-32. DOI: 10.1111/j.14765381.2011.01369.x

19. Tan BK, Adya R, Farhatullah S, Lewandowski KC, O'Hare P, Lehnert H. et al.: Omentin-1, a novel adipokine, is decreased in overweight insulin resistant woman with the polycystic ovary syndrome: ex vivo and in vivo regulation of omentin-1 by insulin and glucose. Diabetes. 2008 Apr;57(4):801-808. DOI: 10.2337/ db07-0990

20. Shibata R, Ouchi N, Takahashi R, Terakura Y, Ohashi $\mathrm{K}$, Ikeda N. et al. Omentin as a novel biomarker of metabolic risk factors. Diabetol Metab Syndr 2012, 4:37. DOI: $10.1186 / 1758-5996-4-37$

21. Kataoka Y, Shibata R, Ohashi K, Kambara T, Enomoto T, Uemura Y, et al: Omentin Prevents Myocardial Ischemic Injury Through AMP-Activated Protein Kinase- and Akt-Dependent Mechanisms. J Am Coll Cardiol. 2014 June;63(24):2722-2733. DOI: 10.1016/j. jacc.2014.03.032

22. Lesná J, Tichá A, Hyšpler R, Musil F, Bláha, Sobotka L. et al. Omentin-1 plasma levels and cholesterol metabolism in obese patients with diabetes mellitus type 1: impact of weight reduction. Nutr Diabetes. 2015 Nov;5(11):e183. DOI: 10.1038/nutd.2015.33

23. Dimova R, Tankova T. The Role of Vaspin in the Development of Metabolic and Glucose Tolerance Disorders and Atherosclerosis. Hindawi Publishing Corporation BioMed Res Int. 2015 Apr;1-7.

24. Reaux-Le Goazigo A, Bodineau L, De Mota N, Jeandel L, Chartrel N, Knauf C, et al. Apelin and the proopiomelanocortin system: a new regulatory pathway of hypothalamic alpha-MSH release. Am J Physiol Endocrinol Metab 2011;301:E955-E966. DOI: 10.1152/ ajpendo.00090.2011

25. Maguire JJ, Kleinz MJ, Pitkin SL, Davenport AP. [Pyr1] apelin-13 identified as the predominant apelin isoform in the human heart: vasoactive mechanisms and inotropic action in disease. Hypertension 2009;54:598-604. DOI: 10.1161/HYPERTENSIONAHA.109.134619

26. Soriguer F, Garrido-Sanchez L, Garcia-Serrano S, Garcia-Almeida J M, Garcia-Arnes J, Tinahones F J, et al. Apelin levels are increased in morbidly obese subjects with type 2 diabetes mellitus. Obes Surg 2009;19:15741580. DOI: $10.1007 / \mathrm{s} 11695-009-9955-\mathrm{y}$

27. Attane C, Foussal C, Le Gonidec S, Benani A, Daviaud $\mathrm{D}$, Wanecq E et al. Apelin treatment increases complete 
Fatty Acid oxidation, mitochondrial oxidative capacity, and biogenesis in muscle of insulin-resistant mice. Diabetes 2012;61:310-320. DOI: 10.2337/db11-0100

28. Dray C, Knauf C, Daviaud D, Waget A, Boucher J, Buleon $\mathrm{M}$, et al. Apelin stimulates glucose utilization in normal and obese insulinresistant mice. Cell Metab. 2008; 8:437-445. DOI: 10.1016/j.cmet.2008.10.003

29. Guvenc Y, Var A, Goker A, Kuscu NK. Assessment of serum chemerin, vaspin and omentin-1 levels in patients with polycystic ovary syndrome. J Int Med Res. 2016 Aug; 44(4):796-805. DOI: 10.1177/0300060516645421

30. Guzel EC, Celik C, Abali R, Kucukyalcin V, Celik E, Guzel $\mathrm{M}$ et al. Omentin and chemerin and their association with obesity in women with polycystic ovary syndrome. Gynecol Endocrinol. 2014 Jun;30(6):41922. DOI: $10.3109 / 09513590.2014 .888412$

31. Celik MN, Sogut MU. Experimental investigation of the effect on the chemerin adipokine and obesity of probiotic use in obese rats, Int J Health Serv. 2017;2(2):5864.

32. Eisinger K, Bauer S, Schäffler A, Walter R, Neumann E, Buechler C, et al. Chemerin induces CCL2 and TLR4 in synovial fibroblasts of patients with rheumatoid arthritis and osteoarthritis. Experim Molec Path. 2012 Febr;92(1):90-6.

33. Ganjali S, Sahebkar A, Mahdipour E, Jamialahmadi K, Torabi S, Akhlaghi S et al. Investigation of the Effects of Curcumin on Serum Cytokines in Obese Individuals: A Randomized Controlled Trial. Sci World J. 2014 Febr;1-6.

34. Ciortea R, Mihu D, Mihu CM. Association Between Visceral Fat, IL-8 and Endometrial Cancer. Anticancer Res 2014, 34:379-384.

35. Chan LP, Liu C, Chiang FY, Wang LF, Lee KW, Chen WT, et al. IL- 8 promotes inflammatory mediators and stimulates activation of $\mathrm{p} 38 \mathrm{MAPK} / \mathrm{ERK}-\mathrm{NF}-\kappa \mathrm{B}$ pathway and reduction of JNK in HNSCC. Oncotarget, 2017;8(34),56375-56388. DOI: 10.18632/oncotarget. 16914

36. Naour N, Rouault C, Fellahi S, Lavoie ME, Poitou C, Keophiphath $\mathrm{M}$ et al. Cathepsins in human obesity: changes in energy balance predominantly affect cathepsins in adipose tissue and in circulation. J Clin Endocrinol Metab. 2010 Apr;95(4):1861-8. DOI: 10.1210/ jc. 2009-1894

37. Brissova M, Aamodt K, Brahmachary P, Prasad N, Hong JY, Dai C, et al. Islet Microenvironment, Modulated by Vascular Endothelial Growth Factor-A Signaling, Promotes $\beta$ Cell Regeneration. Cell Metab. 2014 March, 19(3):498-511. DOI: 10.1016/j.cmet.2014.02.001

38. Elias I, Franckhauser S and Fatima Bosch. New insights into adipose tissue VEGF-A actions in the control of obesity and insulin resistance. Adipocyte. 2013 Apr;2(2):109-112. DOI: 10.4161/adip.22880

39. Daltro PS, Alves PS, Castro MF, Azevedo CM, Vascon- celos JF, Allahdadi KJ, et al. Administration of granulocyte-colony stimulating factor accompanied with a balanced diet improves cardiac function alterations induced by high fat diet in mice. BMC Cardiovasc Disord. 2015 Dec;15:162. DOI: 10.1186/s12872-0150154-6

40. Lee Y, Song YS, Fang CH, So BI, Park JY, Joo HW et al. Anti-obesity effects of granulocyte-colony stimulating factor in Otsuka-Long-Evans-Tokushima fatty rats. PLoS One. 2014 Aug;9(8):e105603. DOI: 10.1371/ journal.pone.0105603

41. Fernandez Alvarez KL, Beldi M, Sarmanho F, Rossetti RAM, Silveira CRF, Mota GR, et al. Local and systemic immunomodulatory mechanisms triggered by $\mathrm{Hu}-$ man Papillomavirus transformed cells: a potential role for G-CSF and neutrophils. Nature. 2017 Aug;Scientific Report 7:9002. DOI: 10.1038/s41598-017-09079-3

42. Nov O, Shapiro H, Ovadia H, Tarnovscki T, Dvir I, Shemesh $\mathrm{E}$, et al. Interleukin-1 $\beta$ regulates fat-liver crosstalk in obesity by auto-paracrine modulation of adipose tissue inflammation and expandability. PLoS ONE. 2013 Jan;8(1):e53626. DOI: 10.1371/journal. pone. 0053626

43. Netea MG, Joosten LAB: The NLRP1-IL18 Connection: a stab in the back of obesity-induced inflammation. Cell Metab. 2016 Jan;23(1):6-7. DOI: 10.1016/j. cmet.2015.12.014

44. Reynolds CM, McGillicuddy FC, Harford KA, Finucane OM, Mills KHG, Roche HM. Dietary saturated fatty acids prime the NLRP3 inflammasome via TLR4 in dendritic cells - implications for diet-induced insulin resistance. Mol Nutr Food Res. 2012;56: 1212-1222. DOI: $10.1002 / \mathrm{mnfr} .201200058$

45. Sun Q, Kiernan UA, Shi L, Phillips DA, Kahn BB, Hu FB, et al. Plasma Retinol-Binding Protein 4 (RBP4) Levels and Risk of Coronary Heart Disease: A Prospective Analysis among Women in the Nurses' Health Study. Circulation. 2013 Apr;113:1-24. DOI: 10.1161/ CIRCULATIONAHA.113.002073

46. Ouchi N, Parker JL, Lugus JJ, Walsh K. Adipokines in inflammation and metabolic disease. Nat. Rev Immunol. 2011 Feb;11(2):85. DOI: 10.1038/nri2921

47. Moraes-Vieira PM, Yore MM, Dwyer PM, Syed I, Aryal P, Kahn BB. RPB4 Activates Antigen-Presenting Cells, Leading to Adipose Tissue Inflammation and Systemic Insulin Resistance, Cell Metab. 2014 March;19(3):512-526. DOI: 10.1016/j. cmet.2014.01.018

48. Tan HW, Liu X, Bi XP, Xing SS, Li L, Gong HP, et al. IL-18 overexpression promotes vascular inflammation and remodeling in a rat model of metabolic syndrome. Atheroslerosis. 2010, 208:350-357. DOI: 10.1016/j. atherosclerosis.2009.07.053

49. Murphy AJ, Kraakman MJ, Kammoun HL, Dragoljevic D, Lee MK, Lawlor KE, et al. IL-18 Production from 
the NLRP1 Inflammasome Prevents Obesity and Metabolic Syndrome. Cell Metab. 2016 Jan;23(1):155-64. DOI: 10.1016/j.cmet.2015.09.024

50. Xu X, Wang H, Wang Z, Xiao W. Plasminogen activator inhibitor-1 promotes inflammatory process induced by cigarette smoke extraction or lipopolysaccharides in alveolar epithelial cells. Exp. Lung Res. 2009;35:795805. DOI: $10.3109 / 01902140902912519$

51. Bruun JM, Helge JW, Richelsen B, Stallknecht B. Diet and exercise reduce low-grade inflammation and macrophage infiltration in adipose tissue but not in skeletal muscle in severely obese subjects. Am J Physiol Endocrinol Metab. 2006;290:961-7. DOI: 10.1152/ajpendo.00506.2005

52. Kishore P, Li W, Tonelli J, Lee DE, Koppaka S, Zhang $\mathrm{K}$ et al. Adipocyte-Derived Factors Potentiate $\mathrm{Nu}-$ trient-Induced Production of Plasminogen Activator Inhibitor-1 by Macrophages. Sci Trans Med. 2010 Febr;2(20):15-20.

53. Oki K, Yamane K, Kamei N, Nojima H, Kohno N. Circulating visfatin level is correlated with inflammation, but not with insulin resistance. Clin Endocrinol. 2007;67:796-800. DOI: 10.1111/j.13652265.2007.02966.x

54. Jurdana M, Petelin A, Cernelic Bizjak M, Bizjak M, Biolo G, Jenko-Praznikar Z. Increased serum visfatin levels in obesity and its association with anthropometric/ biochemical parameters, physical inactivity and nutrition. eSPEN Journal. 2013 Apr;8(2):e59-67. DOI: 10.1016/j.clnme.2013.02.001

55. Brown JEP, Onyango DJ, Ramanjaneya M, Conner AC, Patel ST. et al. Visfatin regulates insulin secretion, insulin receptor signalling and mRNA expression of diabetes-related genes in mouse pancreatic $\beta$-cells. J Mol Endocrinol. 2010 March;44:171-178. DOI: 10.1677/ JME-09-0071

56. Olszanecka-Gilinanowicz M, Kocelak P, Nylec M, Chudek J, Zahorska-Markiewicz B. Circulating visfatin level and visfatin/insulin ratio in obese women with metabolic syndrome. Arch Med Sci. 2012 May;8(2):214-218. DOI: 10.5114/aoms.2012.28547

57. Singh M, Benencia F. Inflammatory signals from fat: Visfatin promotes pro-inflammatory activation and leukocyte interaction in endothelial cells. J Immunol. 2017 May;198, Suppl 1:24.

58. Tabata M, Kadomatsu T, Fukuhara S, Miyata K, Ito Y, Endo M. Angiopoietin-like Protein 2 Promotes Chronic Adipose Tissue Inflammation and Obesity-Related Systemis Insulin Resistance. Cell Metab. 2009 Sept;10(3):178-188. DOI: 10.1016/j.cmet.2009.08.003

59. Hirasawa M, Takubo K, Osada H, Miyake S, Toda E, Endo M, et al. Angiopoietin-like protein 2 is a multistep regulator of inflammatory neovascularization in a murine model of age-related macular degeneration. J Biol Chem. 2016 Apr;291(14):7373-85. DOI: 10.1074/jbc.
M115.710186

60. Nakamura K, Sano S, Fuster JJ, Kikuchi R, Shimizu I, Ohshima K, et al. Secreted frizzled-related protein 5 diminishes cardiac inflammation and protects the heart from ischemia/reperfusion injury. J Biol Chem. 2016 Feb;291(6):2566-75. DOI: 10.1074/jbc.M115.693937

61. Ellabbana A, Abdelhakeemb M, Hamdya M, Fathya I. Impact of obesity on functional and laboratory parameters in patients with rheumatoid arthritis. Egypt Rheumatol Rehabil. 2016 Jan;43(1):21-26. DOI: 10.4103/1110-161X.177423

62. Crowson CS, Matteson EL, Davis JM, Gabriel SE. Contribution of obesity to the rise in incidence of rheumatoid arthritis. Arthritis Care Res. 2013 Jan;65(1):717. DOI: $10.1002 /$ acr. 21660

63. Francin PJ, Abot A, Guillaume C, Moulin D, Bianchi A, Gegout-Pottie P, et al. Association between adiponectin and cartilage degradation in human osteoarthritis. Osteoarthritis Cartilage. 2014 Mar 31;22(3):519-26. DOI: 10.1016/j.joca.2014.01.002

64. Koskinen A, Vuolteenaho K, Nieminen R, Moilanen T, Moilanen E. Leptin enhances MMP-1, MMP-3 and MMP-13 production in human osteoarthritic cartilage and correlates with MMP-1 and MMP-3 in synovial fluid from OA patients. Clin Expr Rheum-Incl Suppl. 2011 Jan 1;29(1):57.

65. Perera PM, Wypasek E, Madhavan S, Rath-Deschner B, Liu J, Nam J, et al. Mechanical signals control SOX9, VEGF, and c-Myc expression and cell proliferation during inflammation via integrin-linked kinase, B-Raf, and ERK1/2-dependent signaling in articular chondrocytes. Arthritis Res Ther. 2010 May 28;12(3):R106. DOI: $10.1186 / \operatorname{ar} 3039$

66. Ungur R, Dronca M, Crăciun EC, Rusu RL, Văleanu M, Onac I, et al. Improvement of total antioxidant status, a possible bioeffect of the ultrasound therapy-a pilot study. Rev Rom Med Lab. 2011;19(2/4):177-183.

67. Hui W, Litherland GJ, Elias MS, Kitson GI, Cawston $\mathrm{TE}$, Rowan $\mathrm{AD}$, et al. Leptin produced by joint white adipose tissue induces cartilage degradation via upregulation and activation of matrix metalloproteinases. Ann Rheum Dis. 2012 Mar 1;71(3):455-62. DOI: 10.1136/annrheumdis-2011-200372

68. Kontny E, Zielinska A, Skalska U, Ksiezopolska-Orlowska K, Głuszko P, Maslinski W. Distinct secretory activity and clinical impact of subcutaneous abdominal adipose tissue in women with rheumatoid arthritis and osteoarthritis. Inflammation. 2017 Feb;40(1):106-16. DOI: $10.1007 /$ s10753-016-0459-3

69. Courties A, Sellam J. Osteoarthritis and type 2 diabetes mellitus: What are the links? Diabetes Res Clin Pract. 2016 Dec;122:198-206. DOI: 10.1016/j.diabres.2016.10.021

70. Van Guilder GP, Hoetzer GL, Greiner JJ, Stauffer BL, DeSouza CA. Influence of metabolic syndrome on bio- 
markers of oxidative stress and inflammation in obese adults. Obesity. 2006;14:2127-2131. DOI: 10.1038/ oby. 2006.248

71. Roberts CK, Hevener AL, Barnard RJ. Metabolic syndrome and insulin resistance: underlying causes and modification by exercise training. Compr Physiol 2013 Jan;3(1):1-58. DOI: 10.1002/cphy.c110062

72. Aquilante CL, Kosmiski LA, Knutsen SD, Zineh I. Relationship between plasma resistin concentrations, inflammatory chemokines, and components of the metabolic syndrome in adults. Metabolism. 2008;57:494501. DOI: 10.1016/j.metabol.2007.11.010

73. Leach NV, Dronca E, Vesa SC, Sampelean DP, Craciun EC, Lupsor M, et al. Serum homocysteine levels, oxidative stress and cardiovascular risk in non-alcoholic steatohepatitis. Eur J Intern Med. 2014 Oct 31;25(8):7627. DOI: $10.1016 /$ j.ejim.2014.09.007

74. Saieva C, Peluso M, Palli D, Cellai F, Ceroti M, Selvi $\mathrm{V}$, et al. Dietary and lifestyle determinants of malondialdehyde DNA adducts in a representative sample of the Florence City population. Mutagenesis. 2016 Mar;31(4):475-80. DOI: 10.1093/mutage/gew012

75. Monickaraj F, Gokulakrishnan K, Prabu P, Sathishkumar C, Anjana RM, Rajkumar JS, et al. Convergence of adipocyte hypertrophy, telomere shortening and hypoadiponectinemia in obese subjects and in patients with type 2 diabetes. Clin Biochem. 2012 Nov 30;45(16):1432-8. DOI: 10.1016/j.clinbiochem.2012.07.097

76. Gikas A, Sotiropoulos A, Pastromas V, Papazafiropoulou A, Apostolou O, Pappas S. Seasonal variation in fasting glucose and $\mathrm{HbA} 1 \mathrm{c}$ in patients with type 2 diabetes. Prim Care Diab. 2009 May 31;3(2):111-4. DOI: 10.1016/j.pcd.2009.05.004

77. Csép K. Surrogate Measures of Insulin Resistance in Middle-aged Non-diabetic Subjects. AMM. 2013 Dec;59(6):279-84.

78. McArdle MA, Finucane OM, Connaughton RM, McMorrow AM, Roche HM. Mechanisms of obesity-induced inflammation and insulin resistance: insights into the emerging role of nutritional strategies. Front Endocrinol. 2013 May;4:52. DOI: 10.3389/fendo.2013.00052

79. Tonding SF., Silva FM., Antonio JP, Azevedo MJ, Canani LHS, Almeida JC. Adiposity markers and risk of coronary heart disease in patients with type 2 diabetes mellitus. Nutr J. 2014 Dec;13(1):124. DOI: 10.1186/1475-2891-13-124

80. Rajendran K, Devarajan N, Ganesan M, Ragunathan M. Obesity, Inflammation and Acute Myocardial Infarction-Expression of leptin, IL-6 and high sensitivity-CRP in Chennai based population. J Thromb. 2012 Aug;10(1):13. DOI: 10.1186/1477-9560-10-13

81. Kleinbongard P, Heusch G, Schulz R: TNFalpha in atherosclerosis, myocardial ischemia/reperfusion and heart failure. Pharmacol Ther. 2010;127:295-314. DOI: 10.1016/j.pharmthera.2010.05.002

82. Kanda T, Takahashi T, Kudo S, Takeda T, Tsugawa H, et al. Leptin deficiency enhances myocardial necrosis and lethality in a murine model of viral myocarditis. Life Sci. 2004;75:1435-1447.. DOI: 10.1016/j. lfs.2004.03.012

83. McGaffin KR, Zou B, McTiernan CF, O’Donnell CP: Leptin attenuates cardiac apoptosis after chronic ischaemic injury. Cardiovasc Res. 2009;83:313-324. DOI: 10.1093/cvr/cvp071

84. Liu Q, Yuan B, Lo KA, Patterson HC, Sun Y, Lodish HF. Adiponectin regulates expression of hepatic genes critical for glucose and lipid metabolism. National Acad Sciences. 2012 Sep;109(36):14568-73. DOI: 10.1073/ pnas. 1211611109

85. Arita Y, Kihara S, Ouchi N, Takahashi M, Maeda K, et al. Paradoxical decrease of an adipose-specific protein, adiponectin, in obesity. Biochem Biophys Rec Commun. 1999;257:79-83. DOI: 10.1006/bbrc.1999.0255

86. Ai M, Otokozawa S, Asztalos BF, White CC, Cupples LA, Nakajima K, at al. Adiponectin: an independent risk factor for coronary heart disease in men in the Framingham offspring Study. Atherosclerosis. 2011 Aug;217(2):543-8. DOI: 10.1016/j.atherosclerosis.2011.05.035

87. Tao L, Gao E, Jiao X, Yuan Y, Li S, Christopher TA, et al. Adiponectin cardioprotection after myocardial ischemia/reperfusion involves the reduction of oxidative/ nitrative stress. Circulation 2007;115:1408-1416. DOI: 10.1161/CIRCULATIONAHA.106.666941

88. Bobbert T, Raila J, Schwarz F, Mai K, Henze A, Pfeiffer AF, Schweigert FJ, Spranger J. Relation between retinol, retinol-binding protein 4 , transthyretin and carotid intima media thickness. Atherosclerosis. 2010 Dec;213(2):549-51. DOI: 10.1016/j.atherosclerosis.2010.07.063

89. Xiao Y, Xu A, Hui X, Zhou P, Li X, Zhong H, et al. Circulating lipocalin-2 and retinol-binding protein 4 are associated with intima-media thickness and subclinical atherosclerosis in patients with type 2 diabetes. PLoS One. 2013 Jun;8(6):e66607. DOI: 10.1371/journal. pone. 0066607

90. Horio E, Kadomatsu T, Miyata K, Arai Y, Hosokawa K, Doi Y, et al. Role of Endothelial Cell-Derived Angptl2 in Vascular Inflammation Leading to Endothelial Dysfunction and Atherosclerosis Progression Arteriosclerosis. Arterioscler Thromb Vasc Biol. 2014 Apr;34:1-11. DOI: 10.1161/ATVBAHA.113.303116

91. Lavie CJ, McAuley PA, Church TS, Milani RV, Blair $\mathrm{SN}$. Obesity and cardiovascular diseases: implications regarding fitness, fatness and severity in the obesity paradox. J Am Coll Cardiol. 2014 Apr;63(14):1345-54. DOI: $10.1016 /$ j.jacc.2014.01.022 